
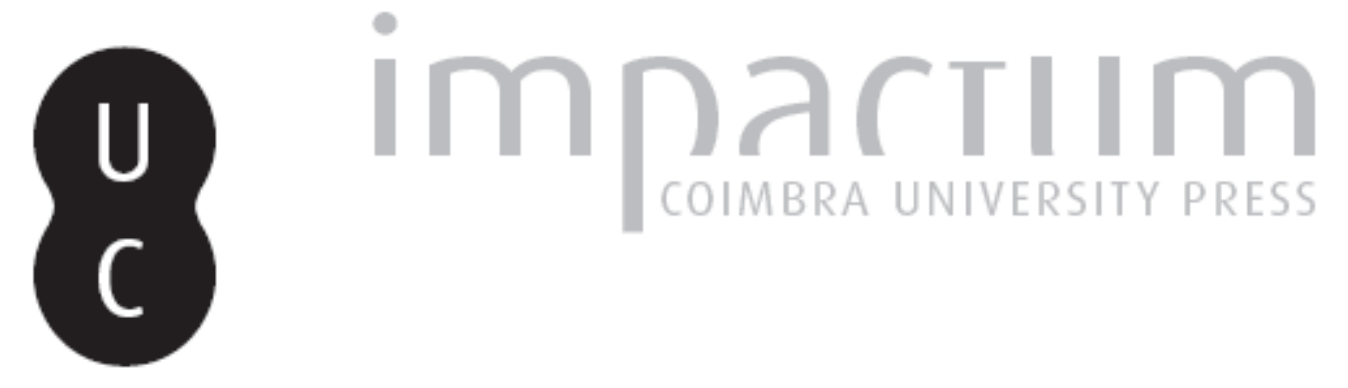

III. Parténio, Paixões de Amor, 2: "Sobre Polimela"

Autor(es): $\quad$ Leão, Delfim F.

Publicado por: $\begin{aligned} & \text { Associação Portuguesa de Estudos Clássicos; Instituto de Estudos } \\ & \text { Clássicos }\end{aligned}$

URL

persistente:

URI:http://hdl.handle.net/10316.2/30355

DOI:

DOI:http://dx.doi.org/10.14195/0872-2110_54_3

Accessed : $\quad$ 26-Apr-2023 14:14:29

A navegação consulta e descarregamento dos títulos inseridos nas Bibliotecas Digitais UC Digitalis, UC Pombalina e UC Impactum, pressupõem a aceitação plena e sem reservas dos Termos e Condições de Uso destas Bibliotecas Digitais, disponíveis em https://digitalis.uc.pt/pt-pt/termos.

Conforme exposto nos referidos Termos e Condições de Uso, o descarregamento de títulos de acesso restrito requer uma licença válida de autorização devendo o utilizador aceder ao(s) documento(s) a partir de um endereço de IP da instituição detentora da supramencionada licença.

Ao utilizador é apenas permitido o descarregamento para uso pessoal, pelo que o emprego do(s) título(s) descarregado(s) para outro fim, designadamente comercial, carece de autorização do respetivo autor ou editor da obra.

Na medida em que todas as obras da UC Digitalis se encontram protegidas pelo Código do Direito de Autor e Direitos Conexos e demais legislação aplicável, toda a cópia, parcial ou total, deste documento, nos casos em que é legalmente admitida, deverá conter ou fazer-se acompanhar por este aviso. 


\section{Boletim de \\ Estudos Clássicos}

Associação Portuguesa de Estudos Clássicos

Instituto de Estudos Clássicos

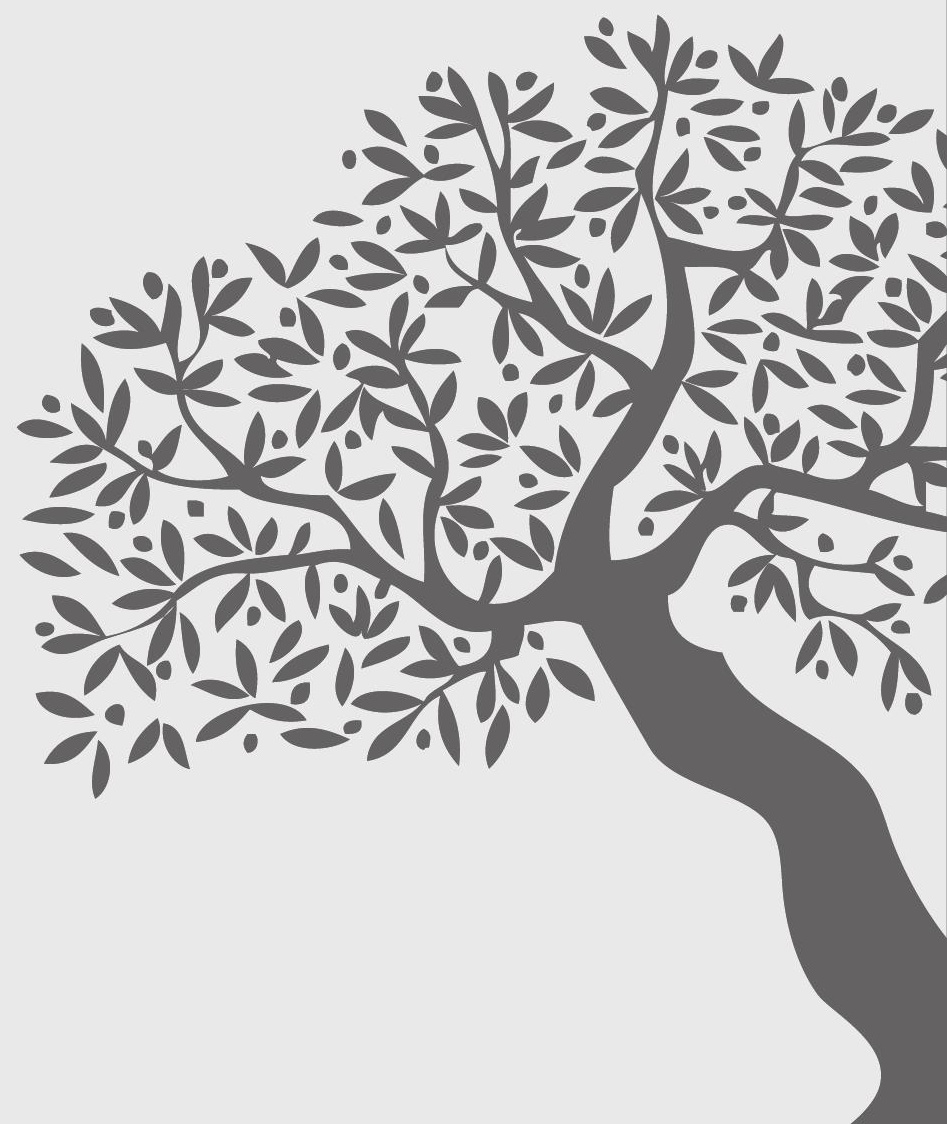

Coimbra

Dezembro de 2010 


\section{PARTÉnio, Paixões de Amor, 2: “SObRe POLIMElA"}

O relato de amor agora evocado deriva, segundo Parténio, do tratamento literário feito por Filetas de Cós, um poeta e estudioso que nasceu à volta de 340 a.C., tendo sido preceptor de Ptolomeu II Filadelfo, que nascera igualmente em Cós. Para além do trabalho que Parténio lhe atribuiu neste passo (Hermes) e onde se narrava a visita de Ulisses à corte de Éolo e os amores que o herói homérico tivera com a filha do deus dos ventos, Polimela, são-lhe ainda atribuídos pela tradição mais alguns trabalhos em poesia e em prosa. Entre a produção poética, da qual se conservam somente algumas notícias e pequenos fragmentos, registam-se títulos como Deméter e Télefo, além de uma colectânea de epigramas (à qual se poderão referir os títulos alternativos de Epigrammata e Paignia, indiciando talvez o seu carácter mais ligeiro). Apesar de pouco haver sobrevivido da sua produção literária, terá ainda assim exercido grande influência sobre a poesia helenística e latina, conforme é atestado por autores que viveram depois dele. ${ }^{1}$

A ideia de que os doze filhos de Éolo (seis rapazes e seis raparigas) haviam casado uns com os outros é um motivo que aparece já tratado em Homero (Odisseia, 10.1-12), sendo que Éolo havia favorecido essa ligação incestuosa, certamente necessária por causa do isolamento da ilha em que viviam. A relação entre Cânace e Macareu, que se teria verificado antes de o pai dar o consentimento para a união entre os filhos, constitui um dos assuntos centrais do Éolo de Eurípides e poderá ter influenciado a abordagem da relação "secreta" entre Ulisses e Polimela. No entanto, o tratamento de Filetas - tal como vem referido por Parténio - não possui o desfecho patético de Eurípides, pois, ao contrário de Cânace, que acaba cometendo suicídio por instigação do pai, Polimela encontra a felicidade ao lado de um outro irmão, Diores, que se oferece para a desposar, não obstante a desonra decorrente do relacionamento prévio com Ulisses. ${ }^{2}$ Esta solução menos drástica vai, de

${ }^{1}$ E.g. Propércio, 3.1.1, que evoca precisamente o influxo de Calímaco e de Filetas sobre a sua poesia.

2 Vide Francese (2001) 117-118. 
resto, sendo preparada já pela indicação de que Éolo havia mantido o herói de Tróia muito tempo junto de si (talvez por serem raras as visitas que recebia ${ }^{3}$ ) e de que Ulisses achava 'prazenteira' a situação, em virtude da paixão que entretanto despertou em Polimela e que lhe animava as noites, na ignorância do pai. Tem sido assinalado um possível paralelo entre a reacção da jovem, posterior à partida de Ulisses, e a forma como Virgílio (Eneida, 4.645-651) trata o abandono de Dido por Eneias. É certo que o motivo do envolvimento com os despojos de Tróia se encontra presente em ambos, bem como a proximidade fraterna (neste caso, a irmã de Dido), mas o desfecho é muito diferente: a rainha de Cartago suicida-se e Ana mais não pode fazer que lamentar a sua morte; em Parténio, porém, o potencial desfecho violento é afastado pela reposição da ordem, com a substituição de Ulisses por Diores, sem que o incesto entre irmãos seja, portanto, motor de tragicidade. ${ }^{4}$

\section{Texto}

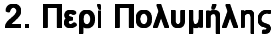

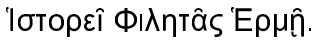

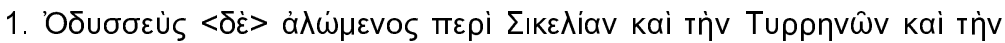

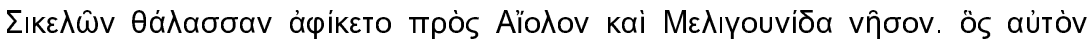

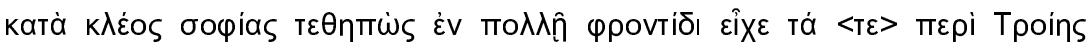

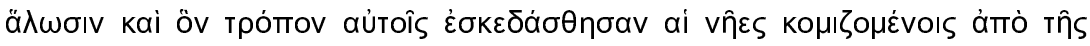

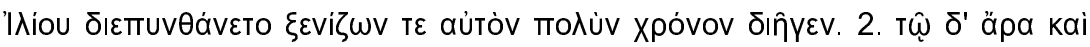

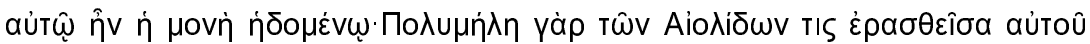

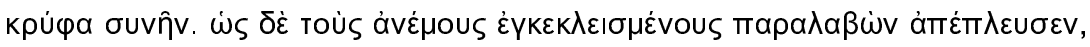

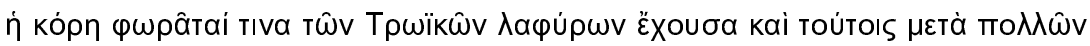

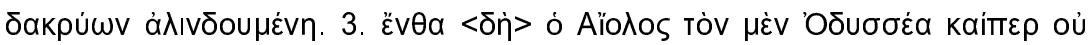

3 A curiosidade de Éolo relativamente ao destino de Tróia e ao regresso dos heróis que haviam disputado a cidade, bem como a forma atenciosa como Ulisses é recebido pelo senhor dos ventos, encontram-se já presentes na Odisseia (10.14-26).

4 Paralelo assinalado em primeiro lugar por Clausen (1976), mas que não o chega a comentar; vide Francese (2001), 127-128 e, sobre a recorrência do tema do incesto em Parténio, 138-143. 


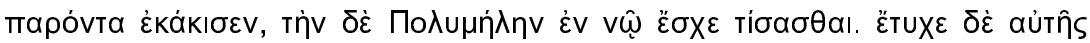

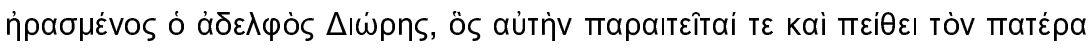

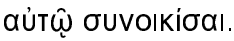

\section{Tradução}

\section{Sobre Polimela}

O episódio é relatado por Filetas no Hermes.

1. Ulisses, nas suas errâncias em torno da Sicília, do Mar Tirreno e do Mar Siciliano, acabou por chegar junto de Éolo, na ilha de Meligúnis. Este tinha-o em muita consideração, devido à sua fama de astúcia, e acolheu-o com grande deferência. Pediu-lhe então pormenores sobre a captura de Tróia e sobre a forma como haviam sido dispersados os barcos que traziam os Gregos de Ílion, mantendo-o junto de si como hóspede durante um longo período. 2. Ora a estadia revelava-se agradável também para Ulisses, pois entretanto Polimela, uma das filhas de Éolo, tinha-se apaixonado pelo visitante, com quem andava a dormir em segredo. Assim que Ulisses zarpou, levando consigo os ventos que Éolo para ele guardara, a jovem foi encontrada com alguns dos despojos de Tróia, desfeita em pranto e a rebolar-se no meio deles. 3. Em consequência, Éolo pôs-se a invectivar fortemente Ulisses, apesar de ele não estar presente, e formulou o propósito de dirigir o castigo contra Polimela. Aconteceu, no entanto, que o irmão dela, Diores, se apaixonara pela jovem, tendo intercedido por ela e convencido o pai a deixar que a irmã vivesse com ele.

\section{BIBLIOGRAFIA CITADA}

CLAUSEN, Wendell, "Virgil and Parthenius", Harvard Studies in Classical Philology 80 (1976) 179.

FRANCESE, Christopher, Parthenius of Nicaea and Roman Poetry (Frankfurt am Main, 2001).

DELFIM F. LEÃO 